\title{
OPPORTUNITIES FOR REDUCTION OF ENERGY CONSUMPTION IN THE LIFE CYCLE OF BIODIESEL OBTAINED FROM MICROALGAE SCENEDESMUS SP.
}

\author{
Virginija Skorupskaite, Violeta Makareviciene \\ Aleksandras Stulginskis University \\ E-mail: violeta.makareviciene@asu.lt
}

Received 2014-06-12, accepted 2014-09-12

\begin{abstract}
The article considers the opportunities for reduction of energy consumption in the life cycle of biodiesel obtained from microalgae oil. Results show that by introducing technical glycerol and substrate leftover after production of biogas into the microalgae growth media energy consumption can be significantly reduced. Production of biogas from de-oiled microalgae improves the energy balance of the life cycle of biodiesel obtained from microalgae oil. It is impossible to obtain fuel containing more energy than would be used in the process of production if microalgae for biodiesel production are cultivated in conventional growth media. Only by subjecting microalgal biomass for production of gaseous and liquid biofuel (biodiesel and biogas) the total energy consumption is lower and equals to $65802.03 \mathrm{MJt}^{-1}$ than energy value of biofuel, i.e. $79083.32 \mathrm{MJt}^{-1}$. In this case the fossil energy ratio (FER) for biodiesel reaches 1.2.
\end{abstract}

Microalgae, energy consumption, biodiesel, fossil energy ratio.

\section{Introduction}

Aiming to increase the use of renewable energy resources in the transport sector and understanding that utilisation of traditional agricultural food raw materials for production of biofuel can lead to negative economic, social, and environmental effects, the European Commission encourages development of "third generation biofuels" production and usage. These biofuels are obtained from microalgal biomass or lipids that can be used in biodiesel synthesis. The advantage of algae over available raw materials used in biodiesel production lies in the possibility to grow algae in uncultivated and infertile areas that are unsuitable for cultivation of agricultural plants and in areas designated for industrial use as well as on very limited land surface-areas (Pokoo-Aikins et al., 2010), which is why algae do not compete for land with the biomass cultivated for food production (Brennan and Owende, 2010).

Compared to other raw materials, algae are marked by high oil output per unit of surface-area: it is possible to obtain up to several times higher amount of oil comparing with oil plants grown on a territory of the same size (Chisti, 2007, Schenk et al., 2008). Moreover, given favourable conditions, these microorganisms can grow extraordinarily quickly (the amount of their biomass can double over one 
day (Chisti, 2007; Hu et al., 2008)) while at the time of the exponential multiplication phase, when there is enough food material and the amounts of metabolism products are low, algae cells can divide as fast as every 3.5 hours (Chisti, 2007).

Studies of use of algal biomass and oil in energy production have gained momentum in the past years, however, energy consumption for algae cultivation still remains high. Biofuels used in the EU countries have to comply with sustainability criteria and the fossil energy ratio (FER) of fuel has to be higher than one, i.e. the amount of energy used in production of biofuel has to be lower than the amount of energy generated in the fuel (calorific value). Evaluation of the life cycle of algae oil methyl esters (AME) has shown that the biggest energy consumption in production of such biodiesel is allocated in drying and oil extraction. H.H. Khoo et al. have identified that oil extraction makes up $85 \%$ of all energy demand while production of biomass and the fuel itself only make up $13 \%$ and 2\% respectively (Khoo et al., 2011). Moreover, according to the data of the same study, for each $\mathrm{MJ}$ of produced fuel $4.44 \mathrm{MJ}$ of fossil energy are spent $\left(R_{I}=0.22\right)$, when algae oil content is $25 \%$. According to the authors of the aforementioned article, optimistically, if the amount of oil were to be increased to $45 \%$ and energy expenses for oil extraction were to be halved, the fossil energy ratio would be equal to 0.6. According to certain scientific data, the FER of the fuel obtained from the oil of Haematococcus p. and Nannochloropsis algae is equal to 0.4 and 0.09 respectively (Razon and Tan., 2011).

Means of reducing energy consumption throughout all of the fuel life cycle stages are being sought in order to reduce energy consumption and increase the fossil energy ratio: usage of less nitrogen at the algae growth stage (Lardon et al., 2009), at the stage of biomass preparation for fuel production, including oil extraction, replacement of old technologies with new ones and combine several different biomass processing methods (Xu et al., 2011).

Based on life cycle evaluation data, it is possible to choose more efficient technologies for obtainment and preparation of raw materials and production of biofuels thus reducing the negative effect of the product upon the environment at every stage of its life. The purpose of our work was to assess the energy inputs occurring in the life cycle of biodiesel produced from Scenedesmus sp. microalgae oil by applying conventional algae cultivation and processing methods and replacing part of the nutrient materials with suitable waste as well as producing biogas along with the biodiesel.

\section{Materials and Methods}

Algae oil methyl esters life cycle analysis (LCA) was performed by applying the methodology provided in ISO 14040-14049 standards. Energy consumption for growing, preparing, and processing of raw materials into biofuel was evaluated aiming to calculate the fossil energy ratio of the AME. Total energy consumption was calculated for production of 1 ton of AME. A closed tube-reactor suitable for cultivation of algae in our climate conditions was chosen to assess microalgae 
growth. Energy demand for microalgae growth comprises electric energy (for pump operation) and energy accumulated in chemical materials. Electric energy consumption was assessed with regard for technical data of constituent reactor equipment as well as duration of electrical energy use. The energy accumulated in chemical materials making up the nutritious environment for algae was calculated based on our own experience and that of Grain Processing Institute (IGV Institut für Getreideverarbeitung $\mathrm{GmbH}$, Nuthetal OT Bergholz-Rehbrücke, Germany) as well as based on energy equivalents of used chemical materials.

The stage of raw material preparation for biofuel production comprises concentration and drying of microalgal biomass and extraction of oil. Centrifugal method was chosen for algal biomass concentration with biomass drying done with Delta drying equipment. Chemical extraction method was adopted for extraction of oil from biomass. Electric and heat energy expenses at the stage of raw material preparation were calculated based on manufacturers' data.

Lithuania does not produce biodiesel from algae oil, therefore, its production expenses are assessed based on the biodiesel production technology employed by JSC "Vaizga" and specification of the equipment they use. Electric and heat energy consumption for microalgae oil transesterification with methanol and energy accumulated in chemical materials were assessed based on the data provided in the dissertation by E. Sendžikienè (2005).

One of the main biodiesel life cycle evaluation parameters is fossil energy ratio (FER), calculated according to the following formula:

$$
F E R=\frac{E_{B}}{E_{p}+E_{g}}
$$

where:

$E_{B}-\mathrm{AME}$ calorific value heat value, $\mathrm{MJ} \mathrm{t}^{-1}$ of biofuel;

$E_{p}$ - energy consumption in obtainment of raw materials and their preparation for biofuel production, $\mathrm{MJ} \mathrm{t}^{-1}$ of biofuel;

$E_{g}$ - energy consumption in oil transesterification (heat and electrical energy consumption and energy accumulated in chemical materials), $\mathrm{MJ} \mathrm{t}^{-1}$ of biofuel.

Energy consumption in obtainment of raw materials and their preparation for biofuel production $\left(\mathrm{E}_{\mathrm{p}}\right)$ comprise:

$$
E_{p}=E_{a}+E_{s}+E_{d z}+E_{e}+E_{t r}
$$

where:

$E_{a}$ - energy consumption for growing of microalgal biomass (electrical energy required to maintain circulation inside the bioreactor and withdraw biomass from the bioreactor and energy used for production of chemical materials making up the nutritious environment), $\mathrm{MJ} \mathrm{t}^{-1}$ of biofuel;

$E_{s}$ - electric energy consumption for algal biomass concentration, $\mathrm{MJ} \mathrm{t}^{-1}$ of biofuel;

$E_{d z}$ - energy consumption for drying of biomass, $\mathrm{MJ} \mathrm{t}^{-1}$ of biofuel;

$E_{e}$ - energy consumption for extraction of oil, $\mathrm{MJ} \mathrm{t}^{-1}$ of biofuel;

$E_{t r}$ - energy consumption for transporting of algae oil to biofuel production facilities, $\mathrm{MJ} \mathrm{t}^{-1}$ of biofuel. 


\section{Results and Discussion}

Fossil energy ratio (FER) was identified through analysis of algae oil methyl esters (AME) production life cycle. To this end energy expenses encompassing the stages of raw material cultivation, its preparation, oil extraction, its transportation to biofuel production facilities, and biofuel production were assessed. Calculations of FER assess not only the energy stored in 1 ton of AME but also the energy obtained from remaining de-oiled biomass after production of biogas. It is assumed that the processes of microalgae cultivation, cultivated biomass preparation, oil extraction, and biogas production from the remaining de-oiled biomass are carried out in the same place with only the oil extracted from the biomass being transported to fuel production facilities.

The results of our earlier studies have shown that the cost of microalgae cultivation can be reduced by introducing biogas by-product, a substrate remaining after anaerobic biomass processing, into the growth medium (Makareviciene et al., 2012) and the amount of oil can be increased by adding $2 \mathrm{~g} \mathrm{l}^{-1}$ of technical glycerol into the growth medium (Makareviciene et al., 2012), thus the following two alternatives were considered in the course of analysis of life cycle of biodiesel obtained from microalgae oil:

- algae cultivation is carried out in a modified BG11 environment $+2 \mathrm{~g}^{-1}$ of technical glycerol;

- algae are grown in the liquid fraction of substrate left after biogas production $+2 \mathrm{~g} \mathrm{l}^{-1}$ of technical glycerol.

The results of our algae cultivation and oil accumulation studies show that the amount of oil in the biomass when growing algae in a BG environment $+2 \mathrm{~g} \mathrm{l}^{-1}$ of technical glycerol reaches $16 \%$ while growing in substrate after biogas production $+2 \mathrm{~g} \mathrm{l}^{-1}$ of technical glycerol produces $18 \%$ of oil in algae biomass. The former, where the biomass accumulates $16 \%$ of oil, requires growing $6250 \mathrm{~kg}$ of biomass to produce 1 ton of AME, while the latter requires $5555.6 \mathrm{~kg}$. Circulation of algae slurry within the reactor, supply of nutrients, and withdrawal of cultivated biomass from the reactor are done with the help of pumps. According to reactor manufacturers' data, an eccentric $37 \mathrm{~kW}$ pump (maximum efficiency of $1000 \mathrm{~m}^{3} \mathrm{~h}^{-1}$ ) is used for maintaining algae circulation inside the reactor with a 5.5 $\mathrm{kW}$ pump employed for supply of nutrients and withdrawal of biomass (maximum efficiency of $\left.150 \mathrm{~m}^{3} \mathrm{~h}^{-1}\right)$. It is assumed that the algae slurry moves along reactor tubes (diameter of $0.06 \mathrm{~m}$ ) at a rate of $0.1 \mathrm{~m} \mathrm{~s}^{-1}$.

In the case of first alternative total energy consumption at the algae cultivation stage comprises the energy used for production of chemical materials intended for establishment of a nutritious environment as well as electric energy demand. Energy consumption for production of chemical materials were calculated using energy equivalents of chemical materials.

It is evident from the study results provided above that algal biomass can be obtained by utilising liquid waste (liquid fraction of substrate left after biogas production) for cultivation of algae after adjustment of nutritious material 
concentrations contained therein. In the case of second alternative cultivation of algae in liquid waste eliminates the need for chemical materials (energy consumption for chemical materials decrease).

Total energy consumption for growing of algal biomass to obtain 1 ton of AME are provided in Figure 1. Based on study result data, using liquid waste for algae cultivation reduces energy demand for biomass cultivation by up to $35 \%$ when compared to energy demand in the case of BG11 nutrition media usage for algae cultivation.

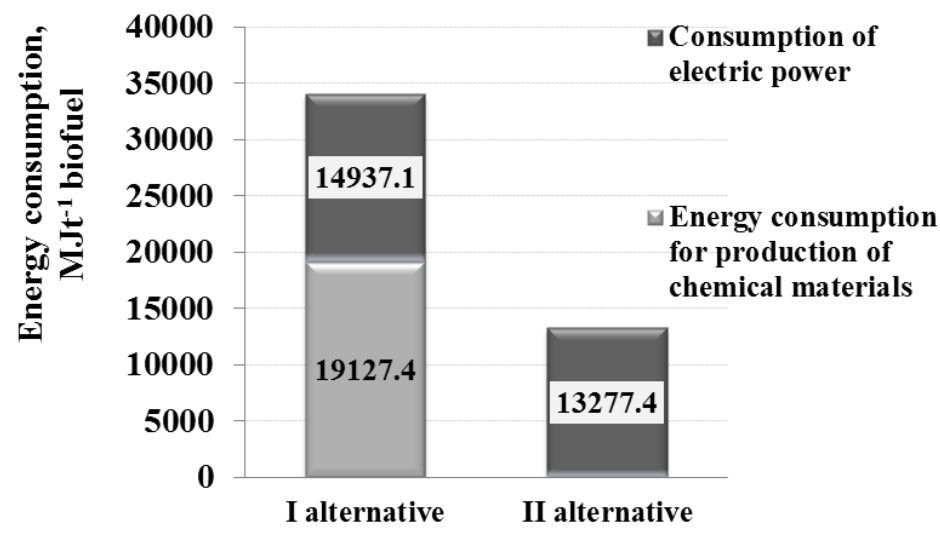

Fig. 1. Energy consumption for production of algal biomass

Cultivated biomass is concentrated by removing a large part (80-90\% (Chen et al., 2011)) of intercellular moisture. Industrial concentration of algal biomass usually employs centrifuges. After considering algal biomass processing technologies, we chose Evodos Type 25 dynamic precipitator (centrifuge) of the EVODOS (Netherlands) company for the purposes of this analysis. Selection of this equipment for the analysis is due to this new generation precipitator using less energy than other regular equipment: $0.95 \mathrm{kWh} \mathrm{m}^{-3}$ of electric energy for biomass separation and $0.25 \mathrm{kWh} \mathrm{m}^{-3}$ of electric energy for pump operation (a total of 1.2 $\mathrm{kWh} \mathrm{m}^{-3}$ for algae slurry while regular centrifuges use $8 \mathrm{kWh} \mathrm{m}^{-3}$ (Stephenson et al., 2010)). It is also marked by high concentration efficiency (separation of algal biomass from the cultivation environment reaches $90-99 \%$, biomass is concentrated to $30 \%$ of dry mass or more).

When performing AME life cycle analysis it was assumed that at this stage the microalgal biomass is concentrated to $30 \%$ of dry mass. In the case of alternative $\mathrm{I}, 1250 \mathrm{~m}^{3}$ of biomass slurry have to be concentrated up to $30 \%$ of dry mass and in the case of alternative II, $1111.11 \mathrm{~m}^{3}$.

Total quantities of energy spent in concentration of microalgal biomass per alternatives I and II are provided in Table 1. 
Table 1. Total energy consumption to obtain 1 ton of AME

\begin{tabular}{|c|c|c|}
\hline Life cycle analysis stages & Alternative I & Alternative II \\
\hline \multicolumn{3}{|c|}{ Energy consumption, $\mathrm{MJt}^{-1}$ of biofuel } \\
\hline \multicolumn{3}{|l|}{ Cultivation of algae } \\
\hline Energy consumption for production of chemical materials & 19127.4 & - \\
\hline Electric energy consumption & 7551.0 & 6730.4 \\
\hline \multicolumn{3}{|l|}{ Contraction of algal biomass } \\
\hline Electric energy consumption & 5400.00 & 4800.0 \\
\hline \multicolumn{3}{|l|}{ Drying of algal biomass } \\
\hline Total energy consumption & 28079.7 & 24959.7 \\
\hline \multicolumn{3}{|l|}{ Extraction of oil } \\
\hline Electric energy consumption & 1698.4 & 1509.7 \\
\hline Heat energy consumption & 8084.2 & 7185.9 \\
\hline \multicolumn{3}{|l|}{ Transportation of oil to fuel production facilities } \\
\hline Fuel energy consumption & 135 & 135 \\
\hline \multicolumn{3}{|l|}{ Production of biodiesel } \\
\hline Electric energy consumption & 1459.0 & 1459.0 \\
\hline Heat energy consumption & 1286.2 & 1286.2 \\
\hline Energy consumption for production of chemical materials & 3390.1 & 3390.1 \\
\hline \multicolumn{3}{|l|}{ Production of biogas from remaining de-oiled biomass } \\
\hline Electric energy consumption & 2710.6 & 2352.1 \\
\hline Heat energy consumption & 13843.3 & 12012.2 \\
\hline Total energy consumption & 92764.9 & 65801.9 \\
\hline
\end{tabular}

In order to extract algae oil from algal biomass with chemical solvents the biomass has to contain no less than $92 \%$ of dry matter. Biomass drying consumes large quantities of energy which is why it is very important to choose appropriate equipment consuming the least possible amount of energy for the purposes of evaluating energy consumption for the aforementioned process. Delta drying equipment was chosen for the purposes of evaluation of energy consumption necessary for removal of moisture from algal biomass as it only consumes $2 \mathrm{MJ}$ of energy for $1 \mathrm{~kg}$ of water removing from the biomass (regular equipment consumes 3-6 MJ kg ${ }^{-1} \mathrm{H}_{2} \mathrm{O}$ (Van Gemert, 2009)). In the case of alternative I, $20833.3 \mathrm{~kg}$ of wet biomass have to be dried to $92 \%$ of dry mass, in the case of alternative 2 , $18518.5 \mathrm{~kg}$ of biomass. Total energy consumption for drying of biomass to the necessary grade of moisture per alternative I and II is provided in Table 1.

Extraction of oil from dry microalgal biomass is conventionally performed by using chemical solvents. Hexane is the most common chemical solvent used for this purpose. Due to lack of data on extraction of oil from microalgal biomass by industrial means and considering that the processes of microalgae oil extraction and soy bean oil extraction are similar, equivalents of energy expenses characteristic of the aforementioned process were used in the life cycle analysis. These calculations assume that electric energy consumption will total $0.25 \mathrm{MJ} \mathrm{kg}^{-1}$ for dry biomass while heat energy consumption will make up $1.19 \mathrm{MJ} \mathrm{kg}^{-1}$ for dry biomass (Shirvani et al., 2011). 
The next stage of the life cycle analysis is transportation of the extracted oil to fuel production facilities. The calculations assume that the algae cultivation, biomass preparation, and oil extraction infrastructure is located $50 \mathrm{~km}$ away from the fuel production facilities. Oil is transported in a $2 \mathrm{~m}^{3}$ truck tank consuming 151 of fuel per $100 \mathrm{~km}$. Energy consumption for transportation is calculated with regard for the heat value of the aforementioned diesel which is equal to $36 \mathrm{MJ} \mathrm{l}^{-1}(2009 / 28 / \mathrm{EB}$ Directive). Calculations assume that 1 ton of algae oil produces 1 ton of AME, thus energy expenses for oil transportation will amount to $135 \mathrm{MJ} \mathrm{t}^{-1}$ of biofuel.

Considering that Lithuania does not produce biodiesel from algae oil, assessment of AME production expenses is based on the technology used by one of Lithuania's biodiesel producer JSC "Vaizga". Energy consumption for microalgae oil transesterification with methanol is evaluated based on data provided in the dissertation by E. Sendžikienè (2005). Data about energy consumption required for oil transesterification and purification of obtained product are likewise provided in Table 1. Calorific value of AME used for calculation was determined by applying calorimetric method and equalled to $39600 \mathrm{MJ} \mathrm{t}^{-1}$.

In order to use microalgal biomass cultivated for energy production purposes as efficiently as possible in fuel production, de-oiled biomass remaining after oil extraction can be used to produce biogas. Based on the results of studies of biogas production from de-oiled biomass, $1 \mathrm{~kg}$ of biomass yields about $0.4 \mathrm{~m}^{3}$ of biogas with $62.12 \%$ of methane content. In Case I, wherein microalgal biomass is cultivated using BG11 nutrition media with addition of technical glycerol, oil extraction leaves $5250 \mathrm{~kg}$ of de-oiled biomass that can produce $2121 \mathrm{~m}^{3}$ of biogas. In Case II, wherein microalgae are cultivated in liquid waste with addition of technical glycerol, extraction of 1 ton of oil leaves $4555.6 \mathrm{~kg}$ of biomass which could produce $1840.4 \mathrm{~m}^{3}$ if subjected to anaerobic processing.

Considering that so far biogas is not industrially produced from algal biomass there are no data on the amounts of energy consumed in the process of biogas production and so evaluation of energy consumed at the time of biogas production was based on energy consumption equivalents obtained for biogas production from waste water silt. According to P. Collet et al. (2011) production of $1 \mathrm{~m}^{3}$ of biogas requires $0.36 \mathrm{kWh}$ of electric and $1.81 \mathrm{kWh}$ of heat energy. Electric energy consumption also includes the amount of electrical energy necessary for centrifuge concentration of solid fraction of spent substrate leftover from biogas production that can be used as high quality fertilizer. In the case of alternative II the remaining liquid fraction of spent substrate would be returned to the microalgae cultivation reactor. Information about energy consumption for biogas production is presented in Table 1 . The calorific value of produced biogas is calculated with regard for biogas composition, i.e. the amount of methane in biogas and methane's calorific value which is equal to $34.5 \mathrm{MJ} \mathrm{m}^{-3}$. In the case of alternative $\mathrm{I}$, the calorific value of produced biogas equals $45502.1 \mathrm{MJ}$, for alternative II it is $39483.3 \mathrm{MJ}$.

After evaluating energy consumption in each stage of the life cycle it is evident that in the case of alternative I energy consumption at the stage of algae 
cultivation and drying (see Fig. 2) have substantial influence upon the resultant energy balance. The biggest part of energy consumption, $28.1 \%$, consists of energy spent for biomass drying; algae cultivation makes up $26.7 \%$.

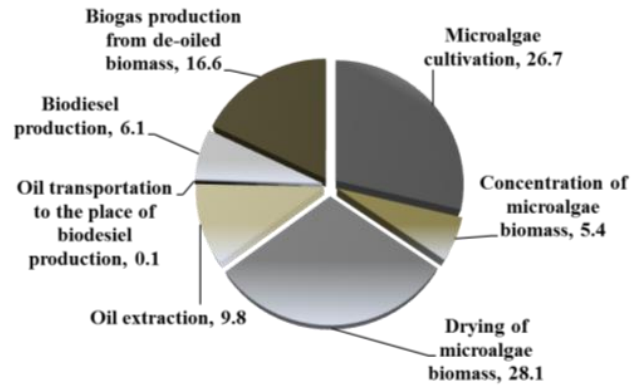

(a)

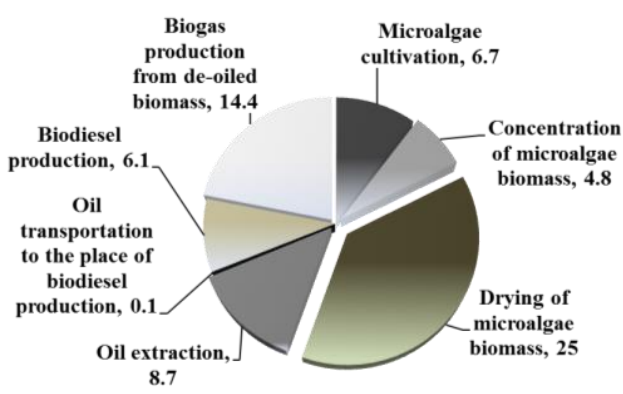

(b)

Fig. 2. Distribution of energy consumption among different stages of the life cycle, $\mathrm{MJ} \mathrm{t}^{-1}$ : (a) - first alternative, (b) - second alternative

Energy consumption for algae cultivation decreases significantly (by 19127.4 $\mathrm{MJ} \mathrm{t}^{-1}$ ) if liquid waste is used for algae cultivation. Just as with alternative I, in the case of alternative II, the largest contributing factor to energy consumption at different stages of the life cycle is the process of biomass drying. As data provided in Figure 2 suggest, distribution of energy consumption among different stages of the life cycle is very similar for both alternatives (except for energy consumption at the stage of raw material generation) although it is not identical. The differences in energy consumption are due to the amount of oil in the cultivated biomass. The amount of biomass necessary to obtain 1 ton of biodiesel decreases and the amount of energy consumed for biomass preparation likewise goes down as the amount of oil in the algae cells increases. A $2 \%$ increase in oil content of algae cells (from 16\% to $18 \%$ ) reduces energy consumption by $11 \%$.

The fossil energy ratio (FER) was calculated for both alternatives (Table 2) based on the amounts of energy consumed for microalgal biomass cultivation, biomass concentration, drying, oil extraction, and production of biodiesel and biogas and according to known energy values of produced biofuels.

Table 2. AME life cycle energy consumption and fossil energy ratio

\begin{tabular}{|l|c|c|}
\hline & Alternative I & Alternative II \\
\hline Total energy consumption, $\mathrm{GJ} \mathrm{t}^{-1}$ & 92.7 & 65.8 \\
\hline Energy obtained from algal biomass, $\mathrm{GJ} \mathrm{t}^{-1}$ & 85.1 & 79.1 \\
\hline Fossil energy ratio (FER) & 0.92 & 1.2 \\
\hline
\end{tabular}

Calculated FER for microalgae grown in the BG11 growing media with added technical glycerol amounted to 0.92 . In the case of alternative II, wherein liquid waste and technical glycerol were used for microalgae cultivation, FER equals 1.2. Life cycle energy balance in excess of one shows that produced biofuel stores more energy than is used in production of biofuel. 
To sum up life cycle analysis results it is necessary to note that use of liquid waste for algae cultivation has several environmental and economic advantages. In terms of environment, this is one of the ways to resolve liquid waste management problems while at the same time implementing solid development principles. In terms of economy, replacement of mineral salts with liquid waste for cultivation of algae makes production of raw materials cheaper.

\section{Conclusions}

Cultivation of microalgae in regular nutritious environments requires large expenditures of energy and materials which is why biodiesel produced from oil of such microalgae does not comply with the requirements posed towards renewable resources: Life cycle consumes more energy than can be obtained from produced biofuels.

Energy consumption can be reduced by supplementing the microalgae cultivation environment with technical glycerol and substrate after biogas production. Production of biogas from de-oiled microalgae improves the energy balance of the life cycle of biodiesel obtained from microalgae oil.

Replacing nutrients present in the growing media with substrate obtained through anaerobic processing of biomass makes energy consumption for biodiesel production exceed the amount of energy stored in the fuel. The value of such fuel's fossil energy ratio is FER $=0.92$.

Complex processing of microalgal biomass for production of biofuels (biodiesel and biogas) makes for $65801.9 \mathrm{MJ} \mathrm{t}^{-1}$ of biofuel in energy consumption. Produced biofuel stores 79083.3 $\mathrm{MJ} \mathrm{t}^{-1}$ of energy. The value of fossil energy ratio is higher than one $-\mathrm{FER}=1.2$, i.e. biofuel stores more energy than was spent to produce the biofuel.

Acknowledgement. This research was funded by a grant (No. MIP-046/2012) from the Research Council of Lithuania.

\section{References}

1. Brennan, L.; Owende, P. 2010. Biofuels from microalgae-A review of technologies for production, processing, and extractions of biofuels and coproducts. Renewable and Sustanable Energy Reviews, 14 (2) 557-577. DOI: 10.1016/j.rser.2009.10.009.

2. Chen, C. Y.; Yeh, K. L.; Aisyah, R.; Lee, D. J.; Chang, J. S. 2011. Cultivation, photobioreactor design and harvesting of microalgae for biodiesel production: A critical review. Bioresource Technology, 102 (1), 71-81. DOI: 10.1016/j.biortech.2010.06.159

3. Chisti, Y. 2007. Biodiesel from microalgae. Biotechnology advances, 25, 294-306. DOI: 10.1016/j.biotechadv.2007.02.001.

4. Collet, P.; Hélias, A.; Lardon, L.; Ras, M.; Goy, R. A.; Steyer, J. P. 2011. Life-cycle assessment of microalgae culture coupled to biogas production. Bioresource technology 102, 207-214. DOI: 10.1016/j.biortech.2010.06.154. 
5. Hu, Q.; Sommerfeld, M.; Jarvis, E.; Ghirardi, M.; Posewitz, M.; Seibert, M.; Darzins, A. 2008. Microalgal triacylglicerols as feedstocks for biofuel production: perspectives and advances. The Plant Journal, 54 (4), 621-639. DOI: 10.1111/j.1365-313X.2008.03492.x.

6. Khoo, H. H.; Sharrat, P. N.; Das, P.; Balasubramanian, R. K.; Naraharisetti, P. K.; Shaik, S. 2011. Life cycle energy and CO2 analysis of microalgae-to-biodiesel: Preliminary results and comparisons. Bioresource Technology, 102 (10), 5800-5807. DOI: 10.1016/j.biortech.2011.02.055

7. Lardon, L.; Helias, A.; Sialve, B.; Steyer, J. P.; Bernard, O. 2009. Lifecycle assessment of biodiesel production from microalgae. Environmental Science and Technology, 43 (17), 6475-6481.

8. Makareviciene, V.; Skorupskaite, V.; Andruleviciute, V. 2012. Biomass and oil production of green microalgae Scenedesmus sp. using different nutrients and growth conditions. Environmental Research, Engineering and Management, 4(62), 5-13.

9. Makareviciene, V.; Skorupskaite, V.; Andruleviciute, V.; Kasperoviciene, J. 2011. Cultivation of microalgae Chlorella $s p$. and Scenedesmus sp. as a potential biofuel feedstock. Environmental Research, Engineering and Management, 3(57), 21-27.

10. Pokoo-Aikins, G.; Nadium, A.; El-Halwagi, M. M.; Mahalec, V. 2010. Design and analysis of biodiesel production from algae grown through carbon sequestration. Clean Technologies and Environmental Policy, 12, 239-254.

11. Razon, L. F.; Tan, R. R. 2011. Net energy analysisof the production of biodiesel and biogas from the microalgae: Haematococcus pluvialis and Nannochloropsis. Applied Energy, 88 (10), 3507-3514. DOI: 10.1016/j.apenergy. 2010.12.052.

12. Schenk P. M.; Thomas-Hall, S. R.; Stephens, E.; Marx, U. C.; Mussgnug, J. H.; Posten, C.; Kruse, O.; Hankamer, B. 2008. Second generation biofuels: high efficiency microalgae for biodiesel production. Bioenergy Resources, 1, 20-43. DOI 10.1007/s12155-008-9008-8.

13. Sendzikiene, E. 2005.Usage of fatty wastes of agricultural origin for the production of biodiesel. Dissertation thesis (04T), Lithuanian University of Agriculture.

14. Shirvani, T.; Yan, X. Y.; Inderwildi, O. R.; Edwards, P. P.; King, D. A. 2011. Life cycle energy and greenhouse gas analysis for algae-derived biodiesel. Energy and Environmental Science 4, 3773-3778. DOI: 10.1039/C1EE01791H.

15. Stephenson, A. L.; Kazamia, E.; Dennis, J. S.; Howe, Ch. J.; Scott, S. A.; Smith, A. G. 2010. Life-cycle assessment of potential algal biodiesel production in the United Kingdom: a comparison of raceways and air-lift tubular bioreactors. Energy \& Fuels, 24 (7) 4062-4077.

16. Van Gemert, G. W. 2009. The Delta dryer. Theoretical and technological development of an energy-efficient dryer for sludge. Dissertation. TU Delft.

17. Xu, L.; Guo, Ch.; Wanga, F.; Zheng, S.; Liu, Ch. Z. 2011. A simple and rapid harvesting method for microalgae by in situ magnetic separation. Bioresource Technology, 102 (21), 10047-10051. DOI: 10.1016/j.biortech.2011.08.021. 